\title{
A PULSE-COUNTING TECHNIQUE FOR THE MEASUREMENT OF DRIFTING SNOW
}

\author{
by \\ H. Tüg \\ (Alfred Wegener Institute for Polar and Marine Research, Postfach 120161 , \\ Columbusstraße, D-2850 Bremerhaven, Federal Republic of Germany)
}

\section{ABSTRACT}

For the study of drifting snow a pulse-counting device was developed. The detector is sensitive to the momentum transfer of individual snow particles to an exposed surface. More than $10^{5}$ particles can be counted per $\mathrm{cm}^{2} / \mathrm{s}$. The sensor is adjusted to snow particles of $30-200 \mu \mathrm{m}$ in diameter and a velocity range of $5-30 \mathrm{~m} / \mathrm{s}$. A multi-channel analyzer system is used for data handling and to display the momentum spectrum in real time.

\section{INTRODUCTION}

Drifting snow is significant for the mass budget of the Antarctic ice cap. For example, the estimated amount of $10^{9} \mathrm{~kg} \mathrm{~km}^{-1} \mathrm{a}^{-1}$ at Mizuho Station (Kobayashi 1978) is not small compared with the mass transport by ice-sheet flow. Now that improved mass-transportation models are available, accurate flux measurements become increasingly important. Until now measurements of drifting snow have employed almost exclusively the principle of trapping the wind-blown snow particles. A great variety of slit-type, cyclone-type, and rocket-type collectors have been used (Budd and others 1966). The many shapes and sizes of these traps have different degrees of efficiency and make it difficult to compare the results. For flux measurements the collected snow must be weighed at regular time intervals. The final drift transport, obtained from integration of drift flux, must be measured at different levels above ground. Drift densities, sometimes needed for models, are derived from flux values if the wind velocity is known at the corresponding level.

Whereas the use of snow traps is rather cumbersome, a real-time processing optical system was designed by Schmidt (1977). It measures the number, velocity, and size of snow particles through a double-beam light pass, but can only be

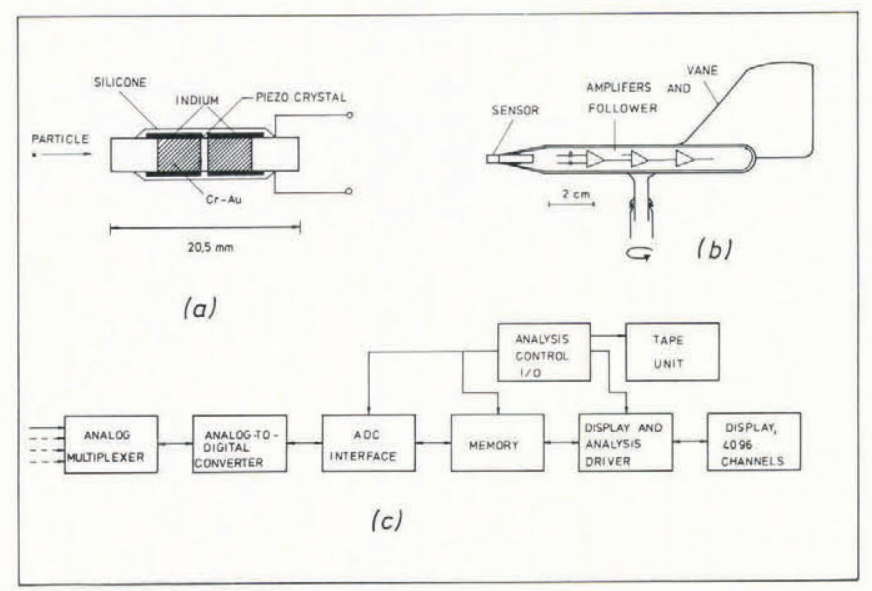

Fig. 1. (a) Sensor head for momentum detection. (b) Sensor housing with vane. (c) Block diagram for data acquisition. used at counting rates less than $1 \mathrm{kHz}$. Since the optical properties of snow particles differ widely with shape and size, the device must be carefully calibrated.

This paper describes an alternative small-size, new type of sensor for continuous observation of drift flux in real time over long periods.

\section{INSTRUMENTATION}

The detector is based on the momentum transfer of individual snow particles to a sensitive surface. Each impact is transformed into a single-voltage pulse proportional to the mass and velocity of the particle. The momentum spectrum is displayed in real time by a computer-controlled multi-channel analyzer system.

\section{Sensor head}

The sensor head, shown in Figure la, consists of two ceramic cylinders $10 \mathrm{~mm}$ long and $4 \mathrm{~mm}$ in diameter, which are mounted symmetrically about a small piezo crystal. A particle impact to the front surface produces longitudinal oscillations of the frequency

$$
f_{n}=n c / 2 l(n=1,2, \ldots)
$$

where $c$ is the sound velocity $(4700 \mathrm{~m} / \mathrm{s})$ and $l$ is the total cylinder length $(20.5 \mathrm{~mm})$. These sonic oscillations are converted to electrical oscillations by the crystal. As the crystal is positioned at the nodal point of the basic oscillation $(n=1)$, it shows a maximum signal amplitude for the second harmonic $(n=2)$ at $230 \mathrm{kHz}$. For the chosen dimensions of the cylinder, higher harmonics were not observed. The resonance frequency was independent of particle mass and velocity. For good conductivity the inner half of the cylinder area is covered with a thin layer of chromium and gold. The main problem was to get only one small, well-shaped voltage pulse from a sensor oscillation, which had a time constant of about $80 \mu \mathrm{s}(18 \mathrm{~Hz})$. To avoid multiple counting of the same event, the damping had to be increased. This was achieved by covering the central part of the cylinder with a thin layer of indium. The time constant could be reduced to about $8 \mu \mathrm{s}$ without significant loss of sensitivity. Compared to many other materials, indium was found to be best suited to our application. It ensures that the time constant remains unchanged at least down to the temperature of $-30^{\circ} \mathrm{C}$ at which the sensor was tested. The measurements will be continued in a cold-room down to $-60^{\circ} \mathrm{C}$.

\section{Electronics}

The sensor housing (Fig. 1b) contains a two-stage amplifier and current booster for cable transmission. The negative pulse of a particle event is amplified and inverted to a positive signal. Because of the short time constant of the sensor head and the insensitivity of the first amplifier to positive voltage, the final detector output is a single pulse in the range $0-10 \mathrm{~V}$. The width and shape of the pulse correspond to the first negative half-wave of the 
original $230 \mathrm{kHz}$ oscillation. The sensor electronics operate at temperatures down to $-55^{\circ} \mathrm{C}$.

The data processing is shown in the block diagram of Figure 1c (a similar technique is also used for nuclear spectroscopy). The events are counted in 4096 separate channels as a function of pulse height and displayed in real time. Several mathematical functions can easily be applied to the momentum distribution. For example, the drift flux is computed from the integral of the spectrum, if the mean particle velocity is taken from separate wind measurements. The electronic equipment is placed in a 19 in housing of about $20 \mathrm{~kg}$. The largest component is a multi-channel analyzer, type 7450 , from EG\&E Ortec.

\section{MEASUREMENTS}

Typical snow-drift particles have a size of $50-150 \mu \mathrm{m}$ and are out of round by less than a factor of 3 (Budd and others 1966). Adopting a weight ratio of 50 for large particles in relation to small ones (Ishimoto and Takeuchi 1984 ) and a velocity range from 5 to $30 \mathrm{~m} / \mathrm{s}$, the dynamic range of the sensor should be at least 300, which corresponds to pulse heights from 0.03 to $10.0 \mathrm{~V}$.

The calibration of the sensor under real field conditions is rather difficult, because the mass and velocity distribution of the particles need to be well known. For laboratory measurements, therefore, the snow was replaced by small grains of sand. As the detector is sensitive to particle momentum only, for easier operation the mass was increased and the velocity decreased relative to field conditions. Particles used for the experiment had a mass of $0.2-2.0 \mathrm{mg}$ and a diameter of $0.3-0.8 \mathrm{~mm}$. Individual grains were weighed in a highly sensitive balance to an accuracy of $\pm 2 \times 10^{-5} \mathrm{~g}$ and were dropped on to the sensor surface from heights between 2 and $20 \mathrm{~cm}$. Under these conditions the correction for air friction, derived from Stokes' law, was $1-4 \%$ of gravitational forces. The measured pulse height was found to be proportional to the fall velocity, as shown in Figure 2. Particles of different mass, which were

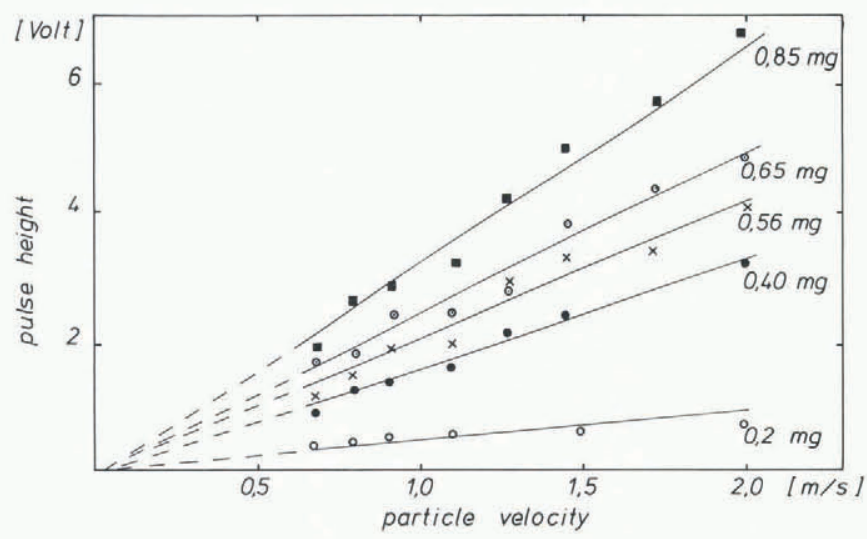

Fig. 2. Pulse height as a function of particle velocity for different grains of sand.

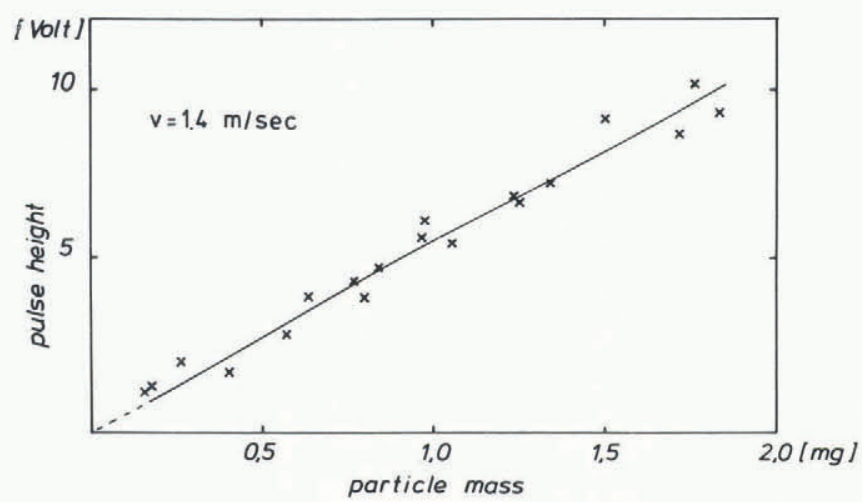

Fig. 3. Pulse height as a function of mass for grain particles of constant velocity $(1.4 \mathrm{~m} / \mathrm{s})$.

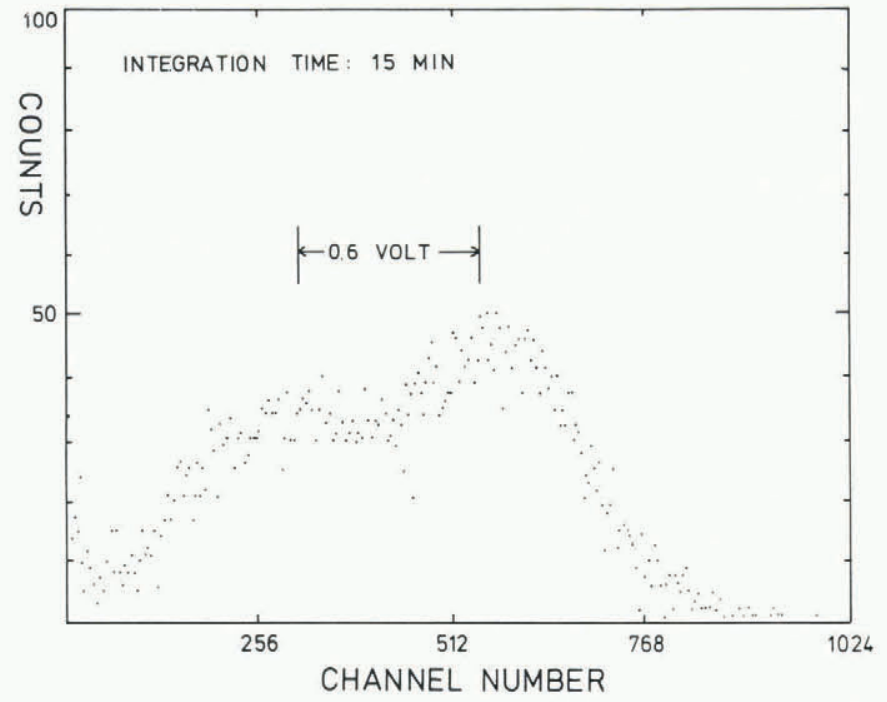

Fig. 4. Momentum spectrum obtained under field conditions with an uncalibrated detector at $15 \mathrm{~m}$ height and a wind velocity of $17 \mathrm{~m} / \mathrm{s}$. Every fourth channel is shown.

dropped from a constant height $(v=1.4 \mathrm{~m} / \mathrm{s})$, showed the same linearity (Fig. 3). Consequently, the pulse height must be proportional to the root of the particle momentum. The amplifier sensitivity was reduced by $25 \mathrm{~dB}$ to keep the input voltage for the pulse analyzer below $10 \mathrm{~V}$.

An uncalibrated version of this device was tested during an Antarctic expedition in September 1986. The sensor was mounted on a ship, about $15 \mathrm{~m}$ above sea-ice level. A momentum spectrum obtained during a snow-storm with a wind speed of $17 \mathrm{~m} / \mathrm{s}$ is shown in Figure 4 . An explanation for the two peaks in the spectrum might be provided by a different mass distribution of drift and precipitation particles. An accumulation of snow particles at the sensor surface was not observed. Ice crystals resulting from sublimation were only found once at the sensor edge, when the humidity was high and the temperature close to $0^{\circ} \mathrm{C}$.

\section{ERRORS}

The laboratory experiments show that the momentum of single particles can be measured with an accuracy of about $5 \%$. Errors were introduced mainly by the uncertainty of particle mass, air friction, and center-to-edge effects of the sensor. The particle shape had no significant influence on the pulse height. Only particles of an extreme shape (needles, discs) showed asymmetrical pulses of varying height, because their impact was not well defined.

For field measurements additional systematic errors become important. One source of error is the effective cross-section (intersecting area/physical area) of the sensor head, due to changes in the trajectories of snow particles before their impact. From the wind profile close to the sensor, the cross-section was estimated to be about 0.95 for particles of $5 \mathrm{~m} / \mathrm{s}$ and $100 \mu \mathrm{m}$ in diameter. The cross-section mainly depends on particle mass and decreases for smaller particles.

Another error arises from variation in snow hardness as a function of temperature. The destruction of particles during the impact might have an influence on the pulse height.

As the measurement is based on pulse-counting technique, dead-time corrections become important with increasing counting rate. With a dead time of $10 \mu \mathrm{s}$ for the drift sensor, the correction is $1 \%$ at $1 \mathrm{kHz}$. At the expected maximum of about $10 \mathrm{kHz}$, derived from flux observations at Mizuho Station (Takahashi and others 1984), the correction would increase to $10 \%$. 


\section{CONCLUSIONS}

The method described looks quite promising for measuring the flux of drifting snow. The sensor can be used to build up larger arrays for drift-transport measurements. It is small in size and can easily be placed in the saltation layer, close to the ground. The calibration procedure will be continued in a wind tunnel, using smaller particles at higher velocities. We are going to integrate into one unit the drift detector and solid-state sensors for wind-speed and wind-direction measurements.

\section{ACKNOWLEDGEMENT}

The author wishes to express his thanks to $\mathrm{Dr} G$. Gravenhorst for his help in solving some hydrodynamic problems.

\section{REFERENCES}

Budd, W.F., W.R.J. Dingle, and U. Radok. 1966. The Bird Snow Drift Project: outline and basic results. In Rubin, M.J., ed. Studies in Antarctic meteorology. Washington, DC, American Geophysical Union, 71-134. (Antarct. Res. Ser., 9.)

Ishimoto, K., and M. Takeuchi. 1984. Mass flux and visibility observed by snow particle counter. Mem. Natl Inst. Polar Res. Special Issue, 34, 104-112.

Kobayashi, S. 1978. Snow transport by katabatic winds in Mizuho Camp area, East Antarctica. J. Meteorol. Soc. Japan, Ser. 2, 56(2), 130-139.

Schmidt, R.A. 1977. A system that measures blowing snow. Fort Collins, CO, U.S. Department of Agriculture. Forest Service. (Res. Pap. RM 194.)

Takahashi, S., H. Ohmae, M. Ishikawa, T. Katsushima, and F. Nishio. 1984. Observations of snow drift flux at Mizuho Station, East Antarctica, 1982. Mem. Natl Inst. Polar Res. Special Issue, 34, 113-121. 